Teaching \& Learning (2020/2021), 13(1), 30-48

\title{
Exploring the Impact of COVID-19 on Greeting Behaviours in Education Through a Lens of Relational Engagement
}

\author{
AARON SMITH \\ University of Waterloo
}

\begin{abstract}
Various impacts of COVID-19 have been explored throughout the literature; however, no research has yet considered the impact of COVID-19 on greetings in education. This paper represents an attempt to address this gap. Using a lens of Relational Engagement, this paper explores the findings of a recent survey $(n=67)$ that asked how teachers have historically greeted students and how they will go about doing so upon return to a physical classroom space. Findings suggest that COVID-19 has significantly impacted teachers' beliefs about greetings in the context of education, that teachers' greeting behaviours are likely to change, and that it is possible if not likely that many teachers may experience various intra- and interpersonal conflicts when they next encounter students face-to-face.
\end{abstract}

\section{Introduction}

"What do you think you will do?" It was an innocuous question from a colleague. We were discussing what school may look like when physical classrooms will begin to reopen after having been closed for months in response to the COVID-19 pandemic. More specifically we were discussing how we will interact with students. Will we greet students with handshakes? If a student offers us a hug, what will we do? What would we have done before COVID-19? Though these questions first arose because of a theoretical sort of conversation, they are not theoretical questions. As schools around the world begin to re-open physical spaces, teachers will encounter students face-to-face for the first time in months, and there is a high likelihood that things will be different.

Since COVID-19 began changing our world, copious amounts of literature have explored these many changes including those to both social and educational facets of life. Viner et al. (2020), for example, explores the epidemiological impacts of school closures as a response to COVID-19. Durkacz (2020) discusses the sudden shift to online education caused by COVID-19 and how, in his perspective, that shift has been an "abject failure" (para. 1). In a piece for TIME 
Magazine, Oakhandler (2020) describes how handshakes and other forms of social greeting may have changed in response to COVID-19. Despite these and many other explorations on social and educational impacts of COVID-19, what remains missing from the literature are explorations of where social and educational worlds intersect. This paper addresses this gap by exploring how COVID-19 has impacted the way teachers experience one of the most common forms of social behaviour in the context of education: greetings.

Greeting behaviours in the context of a physical classroom will be examined by first reviewing relevant literature, introducing a Theory of Relational Engagement, summarizing the findings of a recent survey, and, using the aforementioned Theory of Relational Engagement to consider these findings, discussing what the experience of greeting may be when teachers are able to return to a physical classroom setting.

\section{Greeting Behaviours}

Greeting behaviours vary throughout the world. For example, as noted by Bernieri and Petty (2011), the handshake is common among Western societies, to the extent that it is considered a "near universal behavior" (p. 78). In countries such as France, Italy, and Russia, as well as in parts of both South and Latin America, some version of an "air kiss" is a common form of greeting (Ciolli, 2020). Elsewhere, commonly used forms of greeting include hugs, waves, bows, smiles, head nods, and a variety of formal and informal verbal greetings (Diversity Resources, 2019).

In addition to the cultural influence on greeting behaviours, age can likewise impact the ways in which one greets another. For example, whereas adults may use whatever form of greeting they prefer and/or see as situationally appropriate, be it a more formal greeting such as a handshake or air kiss, or a less formal greeting such as a high five, children are often given more direct instructions on how to greet someone. A parent may tell their child to "give grandma a hug" or to look someone in the eye and to shake their hand (Lee, 2020). Other times, such as in the context of education, children are taught and encouraged to use a variety of greetings such as hugs, high-fives, fist bumps, or thumbs-up (TheCoreCoaches, 2015).

In addition to literature exploring greeting behaviours in general, there is a growing body of literature that seeks to explore greetings in the context of educational settings. For example, in her study on the impact of service-learning projects on teacher-student relationships, Lubchenko 
(2016) observed that it is common for teachers to greet students each morning at the door to the class. Likewise, when exploring the impact of greeting on first-year undergraduate students, Finlay and Young (2006) noted that "it [intentionally greeting others] enhances the student experience and in particular provides a much needed welcome to new students as they start at university" (p. 23). A more recent study by Cook et al. (2018) explored the impact of teachers intentionally and positively greeting students using verbal methods such as using the students' names and expressing interest in the student, and/or nonverbal methods such as handshakes, fist bumps, or pats on the shoulder. When teachers engaged in these sorts of behaviours "to connect relationally with each student and establish a positive classroom climate in which students feel a sense of connection and belonging” (p. 151), researchers found that students spent more time engaged academically and less time engaged in disruptive behaviour.

Supplementing academic research is a wide body of professional literature on how teachers can or should greet students. Larkin (n.d.), for example, suggests a series of steps for implementing a "Meet and Greet" strategy to "help students feel recognized and...that their presence and participation in class is valued" (para. 1). These include positioning oneself by the classroom door before class begins, and, as students enter, and providing both academic and nonacademic check-ins and reminders such as, "Your homework last night was so strong! I'm impressed by how much effort you put into it" or "How are you feeling? I'm excited to see you back to your usual energy today!" (para. 4). Elsewhere teachers are encouraged to ask students questions, make requests of students, offer "a high five, pat on the back, or another appropriate touch-based greeting" (para. 7) and use nonverbal cues toward a student such as a wave or a head nod (PBIS Rewards, n.d.).

In addition to the abovementioned recommended approaches to greeting, the literature contains many other suggestions for teachers as to how they should greet students. For example, commonly recommended approaches include, "greet your students at the door, and then show them to their seat" (Friesen, 2003, p. 56); "shake their hand...(and) make a positive comment or observation" (QPAT, 2018, p. 10); offer a "hug, handshake, high five, or fist bump" (TheCoreCoaches, 2015, para. 3); "as quickly as possible, start calling students by their names" (Donohue, 2015, para. 2); and "pause and connect [with students] about how their day is going" (Cline, 2020, para. 7). Such literature clearly demonstrates that teachers are encouraged to employ a variety of greeting behaviours, including those involving touch. What is notable about 
Exploring the Impact of COVID 19 on Greeting Behaviours in Education

this, however, is that most professional literature that discusses how teachers ought to greet students was written prior to the COVID-19 pandemic.

\section{A Theory of Relational Engagement}

Defined as the ways in which one approaches and participates in relationship with another, relational engagement is something experienced by all persons. A Theory of Relational Engagement, then, is a lens through which one can look to better understand the various inner workings of how one approaches and participates in relationship with another. To be certain, relational interactions are, by definition, comprised of two or more persons; however, this theory is meant to help explain each individual person's experience of an interaction.

It is proposed that relational engagement primarily involves two main components: Relational Perceptions and Relational Actions (Smith, 2017). The concept of Relational Perceptions is meant to describe both what and how one believes, perceives, and even simply thinks about relationship and relational encounters. This includes a variety of perceptions, including beliefs about relationship in general, assessments of whatever specific relationship or even relational encounter one is approaching or in the midst of, and perceptions of people in general and/or the other person(s) within said relationship. These may also include meanings ascribed to relationships or experiences within a relationship; beliefs about how one should approach or behave in a social interaction, how relationships function or ought to function, and the nature of people in both broad and specific manners; and interpretations of another's actions and tendencies within a relationship.

Relational Actions, as its name suggests, describes the many actions, inactions, and reactions one engages in within the context of a relationship or relational encounter. These can include a variety of actions or behaviours, each of which is influenced by relational perceptions. Examples of relational actions might include greeting behaviours, actions meant to communicate something to another, and the many ways in which one presents oneself while interacting with another.

Though relational perceptions and relational actions are discussed separately, in practice they are interconnected (Smith, 2017). Relational engagement is an omnidirectional process in which perceptions and actions each have a direct and reciprocal impact on the other. For example, the beliefs Teacher X holds about people in general, or the perceptions Teacher X 
holds about Student Y have a direct impact on how this teacher acts when with Student Y. Likewise, as Teacher X engages relationally with Student $\mathrm{Y}$ - and as Student Y likewise engages relationally - the perceptions Teacher $\mathrm{X}$ holds of the student and the relationship itself are impacted. Such perceptions then influence Teacher X's actions and so forth.

To understand the impact of COVID-19 on the greeting behaviours of teachers, or in this case to project the impact it may have on such greetings, one must consider the ways it has impacted teachers' perceptions of both people and social behaviours. Further, one must consider how such altered perceptions, as well as COVID-19 itself, will impact the ways in which teachers act in such social, or relational, situations. A Theory of Relational Engagement is thus used as a means of both exploring these sorts of impacts and projecting the possible experience of greetings as teachers re-enter the classroom.

\section{Method}

\section{Respondents}

To better understand the impact of COVID-19 on teachers' approaches to greeting behaviours, a survey was distributed using a snowball sampling method (Shaghaghi et al., 2011). This involved sharing a link to the survey with colleagues across both Canada and the United States who identify as active educators and asking these colleagues to likewise share with their colleagues and so on. As respondents were not asked to identify their geographical location, however, there was no way of tracking where respondents lived or taught.

The aforementioned snowball sampling method produced a sample $(n=67)$ comprised of educators who taught in a variety of educational levels. The majority of respondents taught in primary grades (Grades K-3) $(n=20 ; 29.9 \%)$, followed by Post-secondary $(n=11 ; 16.4 \%)$, Intermediate (Grades 7-10) $(n=11 ; 16.4 \%)$, Junior (Grades 4-6) $(n=8 ; 11.9 \%)$, and Senior (Grades $11-12)(n=7 ; 10.4 \%)$. A further $15 \%$ of respondents $(n=10)$ identified teaching in a number of other settings, including multiple levels (i.e. Preschool/Junior, Junior/Intermediate, Intermediate/Senior, and K-8), Special Education classes, and English and French as Second Language courses for both children and adults. No additional demographic-related questions were asked.

\section{Procedure}


Exploring the Impact of COVID 19 on Greeting Behaviours in Education

To gather information on teachers' greeting behaviours, as well as how these may have been affected by COVID-19, a survey was created using SurveyMonkey. Passive consent was provided through the completion of the survey. Questions on this survey included the following:

1. What sorts of behaviours have you tended to use to greet or welcome students in the past?

2. As you think about returning to your classroom, how do you anticipate your welcoming and//or greeting behaviours changing in light of COVID-19?

3. As you think about the idea of returning to a classroom setting, how do you feel at the prospect of welcoming and/or greeting students?

4. How have you tended to respond in the past if a student offered you a handshake or high five?

5. How have you tended to respond in the past if a student offered you a hug?

6. As you think about the idea of returning to a classroom setting, how do you feel about the possibility of a student offering you a handshake or hug?

7. As you think about the idea of returning to the classroom, how do you think you will respond if a student offers you a handshake or high-five?

8. As you think about the idea of returning to the classroom, how do you think you will respond if a student offers you a hug?

9. What level education do you teach?

For each question, respondents were given a variety of pre-determined answers to choose from as well an option to select "Other" and specify a different answer. For questions \#1-3 and 6, respondents could select as many answers as they felt applied. For questions \#4, 5, and 7-9, 
however, they were limited to choosing one answer. Following the completion of the survey, respondents were given the choice to simply close the survey or, as a thank you for completing the survey, to enter an email address for a chance to win a \$25 Amazon gift card.

\section{Findings}

Findings of this survey suggest that COVID-19 has significantly impacted various relational perceptions held by teachers, as well as the ways in which they are likely to approach relational actions such as greeting behaviours.

\section{Commonly Used Greeting Behaviours Pre-COVID-19}

As seen in Figure 1, teachers identified using a range of greeting behaviours prior to COVID-19. The most used greeting involves giving students "high fives," with approximately $60 \%$ of respondents $(n=40)$ having identified this as a behaviour they have tended to use to greet or welcome students in the past. Following high fives were waves $(n=39 ; 58 \%)$, hugs $(n=$ $24 ; 36 \%)$, and handshakes $(n=16 ; 24 \%)$. A significant number of respondents $(n=24 ; 36 \%)$ identified that they also used a variety of other greeting behaviours including verbal welcomes, nods, smiles, fist bumps, elbow bumps, touches on the shoulder, morning songs, and welcome dances. Analysis of all individual answers shows that in total, 79\% of respondents $(n=53)$ identified having tended to use at least one touch-based greeting behaviour with students. 


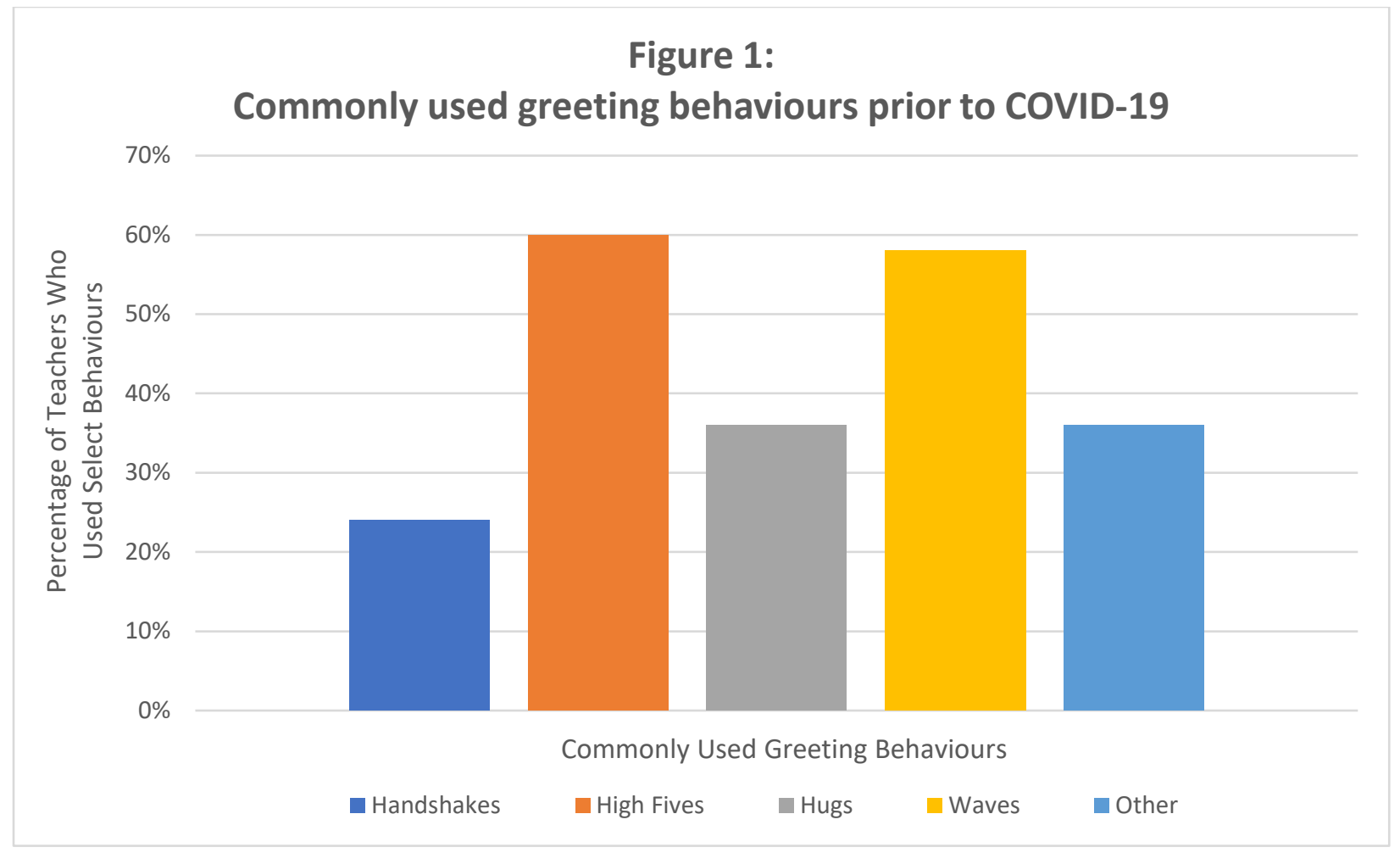

The distribution of certain greeting behaviours, such as high fives and handshakes, is reflective of the population who completed the survey as the majority of respondents $(n=34$; $51 \%$ ) identified as teaching younger children (Preschool - Grade 6). Further analysis of individual responses confirms that the majority of respondents who tended to use high fives taught younger children, whereas the majority of those who tended to use handshakes taught upper level or adult students. 


\section{Anticipated Changes and Feelings About Greeting Behaviours}

As has been noted throughout the literature (e.g. MHRC, 2020; WHO, 2020), one of the more common impacts of COVID-19, particularly on adults, has been that of increased anxiety. Given this, the commonness of touch-based forms of greeting, and the many messages from popular media regarding the dangers of physical touch amid the COVID-19 pandemic (e.g. Besner, 2020; Brean, 2020; Pierce, 2020), respondents were asked how they anticipated their greeting behaviours changing as a result of COVID-19 (Figure 2). Results show that while approximately $19 \%$ of respondents do not anticipate any changes to their greeting behaviours, $58 \%$ of respondents believe they will no longer greet students in a manner that involves touch. An additional $31 \%$ of respondents do not know if or how their greeting behaviours will change.

It is notable that more than $50 \%$ of respondents anticipate no longer greeting students in a manner that involves touch, while another $31 \%$ of respondents are unsure of how they will greet

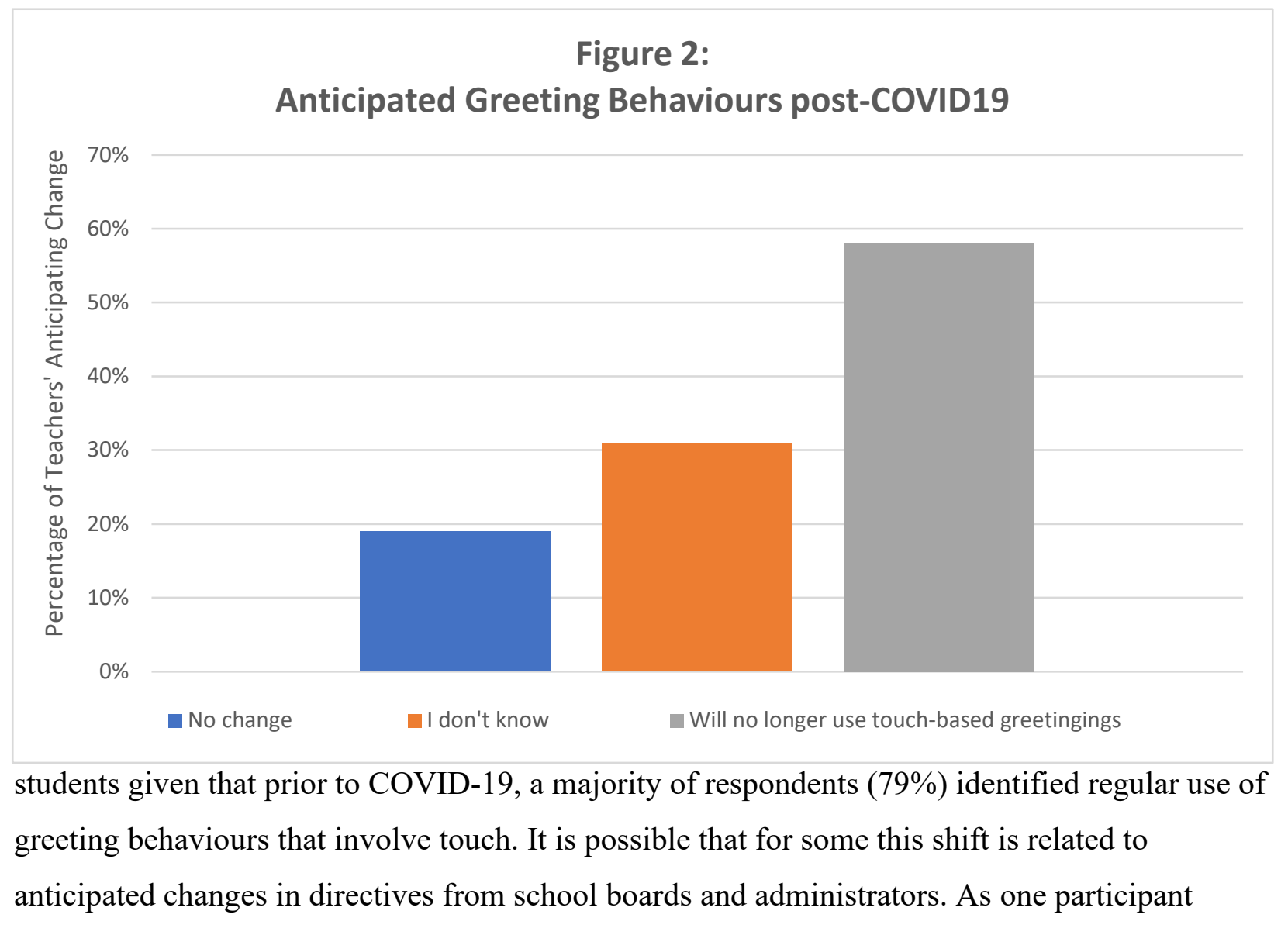


stated, for example, "I don't plan to change [my greeting behaviours], but I realize I need to follow my board's protocol."

A second possible reason for anticipated shifts in greeting behaviours involves respondents' feelings about returning to the classroom. For example, though a small number of respondents $(n=4 ; 6 \%)$ expressed some excitement at the prospect of greeting students upon a return to the classroom, approximately $55 \%$ of respondents $(n=37)$ identified feeling "a little anxious," "very anxious," "terrified," or otherwise worried at the thought. Likewise, though no respondents expressed any sort of excitement at the possibility of a student offering them some sort of touch-based greeting, 63\% $(n=42)$ identified feeling "a little anxious," "very anxious," "terrified," or otherwise worried at the thought of a student initiating some sort of touch-based greeting (Figure 3).

\section{Figure 3:}

\section{Feelings About Greetings Upon Return to Classroom}

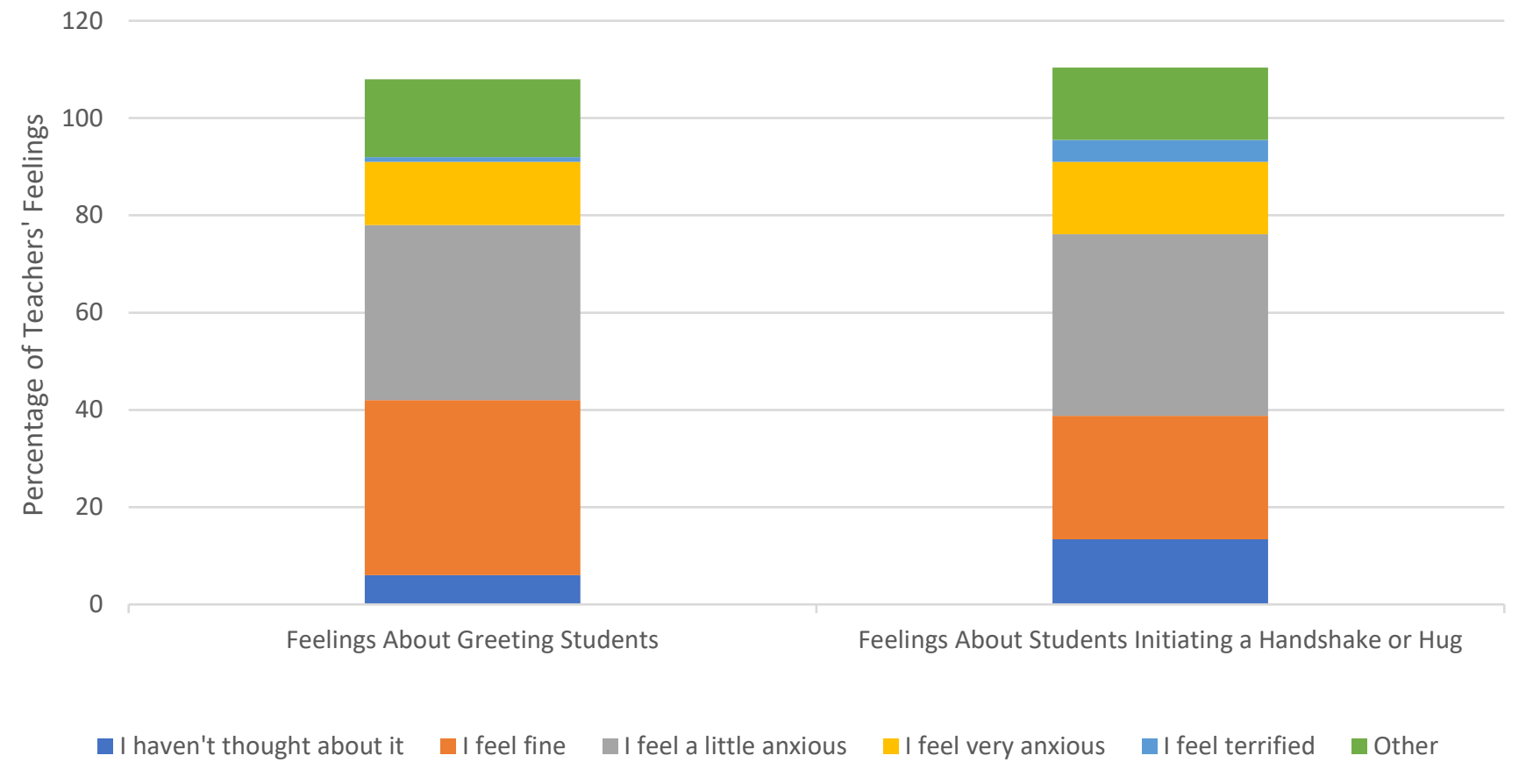

\section{Responding to Student Initiated Touch-Based Greetings}

One of the more notable findings to emerge from the results of this survey involves respondents' tendencies when it comes to responding to student-initiated, touch-based greetings. As seen in Figure 4, approximately $90 \%$ of respondents $(n=62)$ stated that, historically, they 
have accepted a handshake or high five from a student either with or without reservation.

Likewise, approximately $63 \%$ of respondents $(n=42)$ stated that in the past they have accepted a hug from a student either with or without reservation. When asked how they think they will respond in those same situations once they are allowed back into a physical classroom, only $21 \%$ of respondents $(n=14)$ said they would accept a handshake or high five from a student, with only $16 \%(n=11)$ saying they would accept a hug.

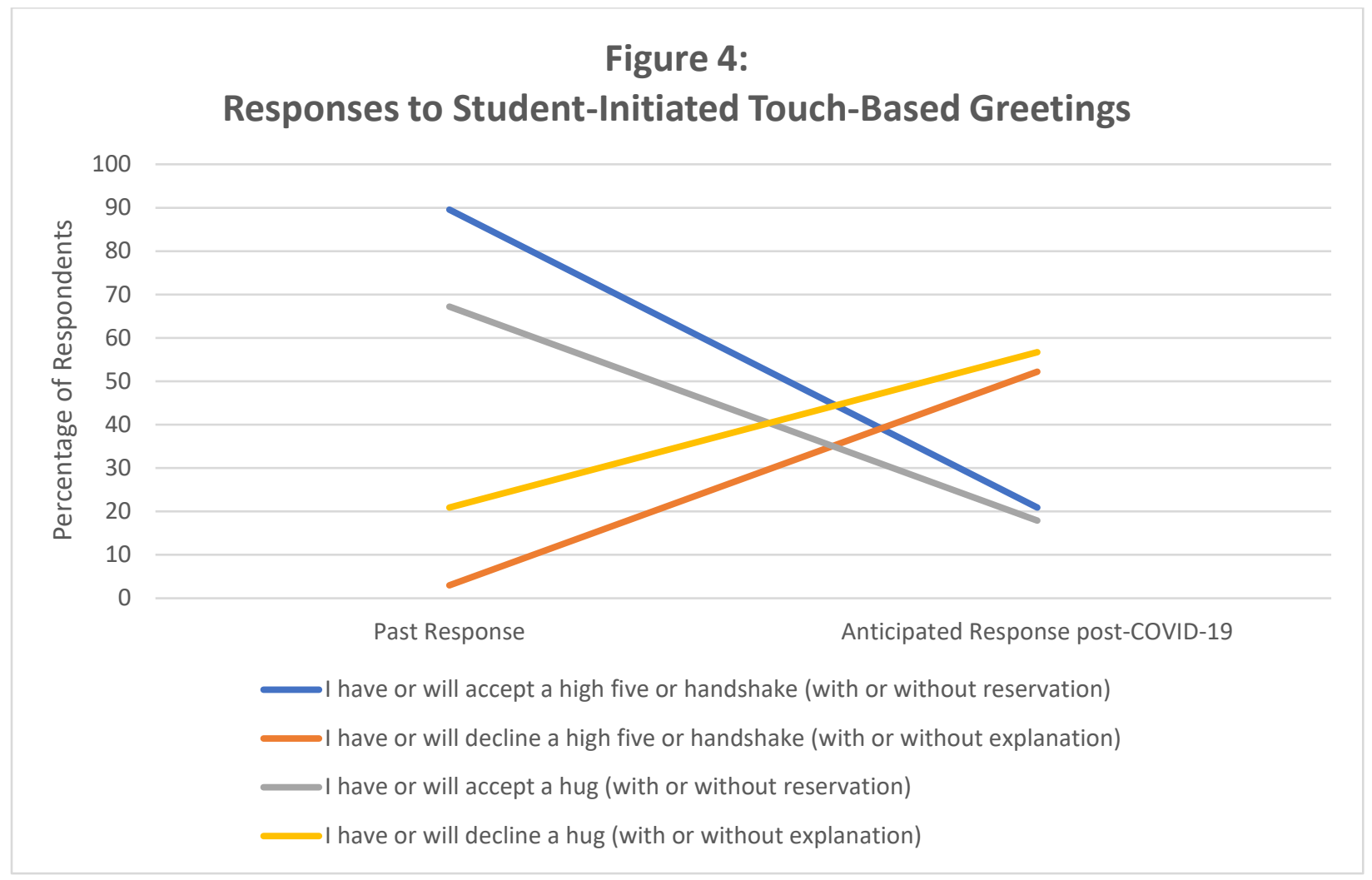

In addition to the shift in respondents' plans to accept a high five, handshake, and/or hug, a second trend emerges from this data. Whereas only $3 \%$ of respondents $(n=2)$ identified that they have tended to actively decline student-initiated handshakes or high fives in the past, 54\% of respondents $(n=36)$ stated that they will decline a high five or handshake when they return to the classroom. Likewise, though $18 \%$ of respondents $(n=12)$ stated that they tended to decline a student-offered hug in the past, $57 \%$ of respondents $(n=38)$ stated that they will decline a hug upon return to the classroom. 


\section{Discussion}

\section{Relational Perceptions}

COVID-19 is impacting teachers in a number of ways. Through the lens of Relational Engagement, the results of this survey seem to suggest that various perceptions teachers have held about students and relationships with students have been challenged by some of the realities of COVID-19. For example, given that the overwhelming majority of respondents tended to accept high fives, handshakes, and even hugs prior to COVID-19, it is possible if not likely that many respondents previously held a relational perception along the lines of: "Even if I myself do not enjoy this form of greeting, my own preference is not as important as is making students feel welcomed and important." One of the impacts of COVID-19, however, seems to have been an alteration to this perception in that the majority of teachers surveyed state that upon return to the classroom, they will likely neither initiate nor reciprocate most touch-based greetings. Such a shift in behaviour suggests that COVID-19 has likewise produced a shift in beliefs or perceptions held by respondents. Whereas this is conjecture, it is possible that the previous sort of relational perception has been changed to one more along the lines of: "While it is important that students feel welcomed, what is more important is that both the student and I are kept safe" or even "ensuring safety is worth the risk of possibly hurting a student's feelings." Through a lens of relational engagement, it seems likely that COVID-19 has impacted numerous relational perceptions, which in turn are likely to impact relational actions.

\section{Relational Actions}

As mentioned, the majority of respondents both initiated and accepted various touchbased greetings prior to COVID-19. As beliefs about what is safe, what is appropriate, what is most important, and even how one is to act in relational or social situations have shifted, so too have relational actions. Two of the more obvious anticipated changes include a decrease in offering or accepting in touch-based greetings, and an increase in active behaviours meant to decline touch-based greetings. Other anticipated changes include an increase in some actions such as offering explanations as to why respondents act in a specific manner, for example declining a greeting or stepping back when a student approaches; offering alternate forms of greeting instead of simply accepting whatever greeting was initiated by a student; and using hand sanitizer following a student-initiated, touch-based greeting, if it is accepted. It is also plausible 
Exploring the Impact of COVID 19 on Greeting Behaviours in Education

that there will be an increase in inaction on the part of respondents as approximately $7 \%(n=5)$ stated that it is likely that they will hesitate, unsure what to do, if a student initiates a high five, handshake, and/or hug.

\section{Intra- and Interpersonal Conflict}

When relational beliefs and perceptions change, and therefore relational actions are altered, the experience for all persons involved in the encounter is likely to be impacted. Through a lens of Relational Engagement, it becomes clear that respondents' perceptions have been impacted by COVID-19, which in turn has led many to wrestle with how they will or ought to act:

- "I don't want to be standoffish with children."

- Translation through a lens of Relational Engagement: I probably should change my behaviours, but I am concerned I will come across as cold and unfriendly.

- "I don't want [students] to feel that a touchless greeting has anything to do with them, but only to do with keeping everyone healthy."

- Translation through a lens of Relational Engagement: Keeping everyone healthy is the most important thing to do, but I am concerned that students will feel like there is something wrong with them or that I am afraid of them.

- " "I feel] sad that I can no longer comfort children that are upset using appropriate comforting like a hug."

$\circ$ Translation through a lens of Relational Engagement: Comforting children when they are upset is important to me, but so is staying safe.

- 'Ifeel anxious about finding an appropriate way of responding that doesn't make [students] shut down."

- Translation through a lens of Relational Engagement: I want to respond to students in a way that makes them feel important and keeps them engaged, but I don't know how to do that.

- "I worry that I will not be able to return the gesture [touch-based greeting], and therefore will be teaching [students] that indirectly this behaviour is wrong."

- Translation through a lens of Relational Engagement: It is important to model appropriate social behaviour, and I am worried what will happen when I don't respond in a like manner but keeping us both safe is more important.

- " "I feel] so torn. I want students to feel comfortable, but not get fired."

- Translation through a lens of Relational Engagement: It is important that students feel comfortable with me, but it is also important to follow the rules. 
Exploring the Impact of COVID 19 on Greeting Behaviours in Education

- "I will be looking to respond in a way that doesn't cause [students] to feel rejected."

- Translation through a lens of Relational Engagement: I want to be safe, but I also want students to know that I appreciate and accept them for who they are.

Though these "Translations through a lens of Relational Engagement" are speculative, they reveal the sorts of inner conflicts that many teachers may experience as they consider, if not encounter, situations in which a touch-based greeting is considered or initiated. Whether these struggles have emerged from COVID-19-related anxiety or any other source, it seems plausible that many teachers are or will experience intrapersonal conflict about perceptions of people and relationships, and actions related to physical proximity and touch.

The second sort of conflict that is likely to emerge as a result of the impact COVID-19 has had on greeting behaviours involves the interpersonal dynamics involved in any relational encounter. As discussed above, some of the shifts in perception caused by COVID-19, such as "whereas students used to be safe, they are now potential carriers and therefore are now more risky than before COVID-19” or “As much as I don't want to hurt a student's feelings, it is even more important that I ensure their and my safety" have likewise impacted the ways in which people act in the context of relational encounters. These include, for example, increases in some actions (i.e. verbal greetings and declining touch-based greetings) and inactions (i.e. hesitating when presented with a touch-based greeting), as well as decreases in other behaviour (i.e. accepting high fives, handshakes, or hugs from students). As challenging as this likely will be for many, what makes this even more potentially problematic is that not only are teachers' perceptions impacted by relational experiences as well as events such as COVID-19, but so too are students' perceptions and actions.

\section{Implications}

The findings of this survey suggest that teachers may not be adequately prepared for the reality that they will soon have to greet students face-to-face. It is possible that though some discussions have started about how and when to reopen physical classrooms, little to no discussion has yet begun regarding what this will be like for teachers. That nearly a third of respondents ( $n=21 ; 31 \%)$ answered "I don't know" when asked how they anticipate their greeting behaviours changing upon return to the classroom, suggests the possibility that some teachers, administrators, and school boards have yet to think about the impacts that COVID-19 
has had on social aspects of teaching, such as greetings. One recommendation from this survey would be for those who work in education to begin discussing not only what greetings should look like, but what this will be like for teachers upon the return to school.

A second, related implication of the findings of this survey appears to be that many teachers are currently struggling at the thought of face-to-face encounters with students. As indicated above, when asked how they feel at the thought of having to greet students upon return to the classroom, more than half of the respondents $(n=41 ; 61 \%)$ indicated that they have not yet thought about it and/or are feeling some degree of anxiety at the prospect. Likewise, more than three quarters of respondents $(n=51 ; 76 \%)$ indicated that they either have not yet thought about and/or are feeling some degree of anxiety at the thought of a student offering them a handshake or a hug upon return to the classroom. A second recommendation to come from this survey, then, is that teachers not only be given a space to process these struggles, but also professional supports, such as counsellors or other therapists, to aid teachers as they deal with their uncertainty and anxiety at the prospect of greetings upon the return to school.

The third and final recommendation to come from this study is for not only teachers, but also all others involved in education to begin actively discussing the matter of greetings in the classroom. In addition to those respondents who indicated uncertainty and/or anxiety at the thought of greeting students, it is likely that there are many others who likewise have not yet thought about this and/or worry at the thought. As one respondent said, "I am only starting to think about [greetings with students] now because of this survey. " It is possible if not likely that this person is not alone in that they have not yet thought about this common experience. Given its importance, however, it is recommended that not only teachers, but also all others involved in education begin to intentionally discuss what greetings in the classroom will look like postCOVID-19.

\section{Limitations}

As with all studies, this study has several limitations that must be acknowledged. First, this study draws on a relatively small sample size. Further, no demographic-related data was sought apart from what level of education one teaches. To generalize the findings from this study, then, not only must the overall sample size be increased, but so should data such as age, 
race, training, location of school, or subjects taught, etc., be collected. Until this is done, it is difficult to say whether any of the findings can be generalized to other teachers.

The second limitation of the current study is that, whereas several questions were asked about respondents' feelings at the thought of greetings upon return to the classroom, no similar questions were asked about respondents' feelings prior to COVID-19. It is therefore impossible to conclusively identify any correlations between respondents' feelings of anxiety, for example, and anticipated changes to greeting behaviours. As such, future research is needed to further explore this and any other outstanding questions on the subject.

\section{Conclusion}

As stated at the onset of this paper, this study was meant to be exploratory in nature. Therefore, while no definitive conclusions can be made about what greeting behaviours may look like for teachers upon their return to a physical classroom, it can be conclusively said, however, that this study has raised to awareness the possibility that COVID-19 will significantly impact teachers' greetings behaviours.

The results of this study suggest that COVID-19 has impacted a number of the perceptions that teachers hold about greetings. Results also suggest that the way teachers will act in the context of greetings in the classroom has likewise been impacted. From this, it seems as though intra- and/or interpersonal conflicts involving teachers and students are possible if not likely. It also seems as though many students, teachers, administrators, and others involved in education have, are, or will encounter questions as to what they will do when schools reopen. As one teacher recently posted in a public online discussion about the impact of COVID-19 on greeting behaviours, "How do I greet (and comfort) my kindergartens...if I can’t hug them?!" (Braendle, 2020). As happened to me, and I suggest will happen to you, this teacher seems to be encountering the very question addressed in this paper: What do you think you will do?

\footnotetext{
Aaron Smith is an Instructor at Renison University College and King's University College, a Registered Psychotherapist at STAR Family Health Team, and the Director of Social Research and Education Group. Aaron has graduate degrees in Theological Studies and Spiritual Care \& Psychotherapy, and is a PhD Candidate in the Faculty of Social Work at Wilfrid Laurier University. Aaron's current research considers the experience of relational engagement in light of the intersecting nature of personal and professional identities.
} 
Exploring the Impact of COVID 19 on Greeting Behaviours in Education

\section{References}

Bernieri, F. J., \& Petty, K. N. (2011). The influence of handshakes on first impression accuracy. Social Influence, 6, 78-87.

Besner, L. (2020, May 22) Can't touch this: Will COVID-19 mean the end of our most intimate sense? The Globe and Mail. Retrieved from:

https://www.theglobeandmail.com/opinion/article-cant-touch-this-will-covid-19-meanthe-end-of-our-most-intimate/

Braendle, C. (2020, June 11) In Facebook [Country 106.7]. Retrieved June 11, 2020, from https://www.facebook.com/country1067/photos/a.133659403341524/4153974297976661 ? type $=3 \&$ theater

Brean, J. (2020, March 26) COVID-19 crisis: With touch now toxic, how do you navigate the consumer world? National Post. Retrieved from: https://nationalpost.com/news/covid-19crisis-with-touch-now-toxic-how-do-you-navigate-the-consumer-world

Ciolli, C. (2020, April 8) Beyond the handshake: How people greet each other around the world. AFAR. Retrieved from: https://www.afar.com/magazine/beyond-the-handshake-howpeople-greet-each-other-around-the-world

Cline, K. (2020, January 9) 5 easy ways to greet students throughout the day. Teachstone. Retrieved from http://info.teachstone.com/blog/5-easy-ways-to-greet-students

Cook, C. R., Fiat, A., Larson, M., Daikos, C., Slemrod, T., Holland, E. A., Thayer, A. J., \& Renshaw, T. (2018). Positive Greetings at the Door: Evaluation of a Low-Cost, HighYield Proactive Classroom Management Strategy. Journal of Positive Behavior Interventions, 20(3), 149-159. https://doi.org/10.1177/1098300717753831

Diversity Resources. (2019). Greetings and customs around the world. Retrieved from https://www.diversityresources.com/greeting-customs-around-the-world/

Donohue, C. (2015, August 5) 8 ways to make students feel welcome on first day of school. neaToday. Retrieved from http://neatoday.org/2015/08/05/8-ways-to-make-students-feelwelcome-on-first-day-of-school/

Durkacz, K. (2020, June 6) Emergency remote learning is a failure. The Hamilton Spectator. Retrieved from: https://www.thespec.com/opinion/contributors/2020/06/06/emergencyremote-learning-is-a-failure.html

Finlay, H.J., \& Young, D (2006) Meeting and greeting new students. CILIP Update, 5 (12). 22 23.

Friesen, L. A. (2003) The beginning teacher's handbook for elementary school. (Master's thesis, University of Lethbridge, Lethbridge, Canada). Retrieved from https://hdl.handle.net/10133/949

Larkin, H. (n.d.) Thresholding to greet students at the door. BetterLesson. Retrieved from: https://betterlesson.com/strategy/152/thresholding-to-greet-students-at-the-door

Lee, K. (2020, May 9) How to help a child feel at ease when greeting people. Verywell Family. Retrieved from: https://www.verywellfamily.com/how-to-teach-a-child-to-greet-peopleproperly-620131

Lubchenko, S. (2016) Service learning creates a positive relationship between teachers and students. Journal of Character Education, 12(1), 81-87. 
Mental Health Research Canada (MHRC) (2020) Mental Health During COVID-19 Outbreak Wave 1. Retrieved from: https:/www.mhrc.ca/wp-content/uploads/2020/05/Full-Reportof-Findings-of-Survey-FINAL.pdf

Oakhandler, M. (2020, May 27) The Coronavirus killed the handshake and the hug. What will replace them? TIME Magazine. Retrieved from: https://time.com/5842469/coronavirus-handshake-social-touch/

Pierce, S. (2020, May 15) Touch starvation is a consequence of COVID-19's physical distancing. Texas Medical Center. Retrieved from: https://www.tmc.edu/news/2020/05/touch-starvation/

PBIS Rewards (n.d.) 5 Simple Ways to Greet Students. Retrieved from: https://www.pbisrewards.com/blog/5-simple-ways-to-greet-students/

Quebec Provincial Association of Teachers (QPAT). (2018) Handbookfor New Teachers. Retrieved from https://qpat-apeq.qc.ca/wp-content/uploads/2018/11/1166-QPATHandbook-for-New-Teacher-E.pdf

Shaghaghi, A., Bhopal, R. S., \& Sheikh, A. (2011) Approaches to recruiting 'hard-toreach' populations into research: A review of the literature. Health Promotion Perspectives, 1(2), 86-94.

Smith, A. (2017). General principles of relational engagement. Unpublished manuscript. TheCoreCoaches (2015) Morning Greetings: Hug, Handshake, High-Five, or Fistbump. Retrieved from https://thecorecoaches.com/2015/06/http-thecorecoaches-com-2015-06when-i-was-classroom-teacher-i-moved/

Viner, R. M., Russell, S. J., Croker, H., Packer, J., Ward, J., \& Stansfield, C. (2020) School closure and management practices during coronavirus outbreaks including COVID-19: A rapid systematic review. The Lancet, 4(5), 397-404. DOI: https://doi.org/10.1016/S2352$\underline{4642(20) 30095-X}$ 
Exploring the Impact of COVID 19 on Greeting Behaviours in Education

World Health Organization (WHO) (2020, March 18) Mental health and psychosocial considerations during the COVID-19 outbreak. Retrieved from:

https://www.who.int/docs/default-source/coronaviruse/mental-healthconsiderations.pdf?sfvrsn=6d3578af 2 